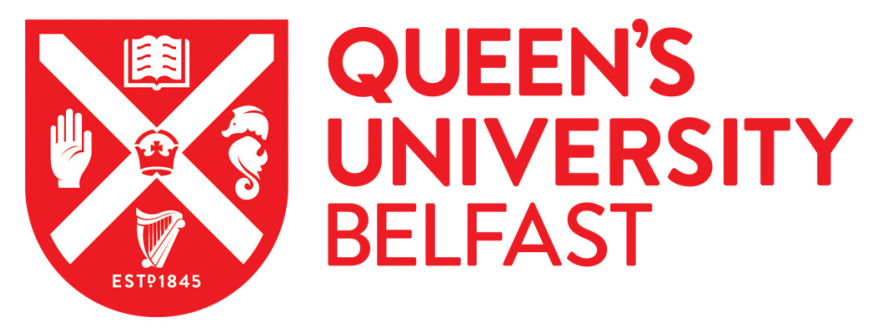

\title{
Attainment grouping as self-fulfilling prophesy? A mixed methods exploration of self confidence and set level among Year 7 students
}

Francis, B., Connolly, P., Archer, L., Hodgen, J., Mazenod, A., Pepper, D., Sloan, S., Taylor, B., Tereshchenko, A., \& Travers, M. -C. (2017). Attainment grouping as self-fulfilling prophesy? A mixed methods exploration of self confidence and set level among Year 7 students. International Journal of Educational Research, 86, 96-108. https://doi.org/10.1016/j.ijer.2017.09.001

Published in:

International Journal of Educational Research

Document Version:

Peer reviewed version

Queen's University Belfast - Research Portal:

Link to publication record in Queen's University Belfast Research Portal

Publisher rights

(c) 2017 Elsevier Ltd. All rights reserved. This work is made available online in accordance with the publisher's policies. Please refer to any applicable terms of use of the publisher.

\section{General rights}

Copyright for the publications made accessible via the Queen's University Belfast Research Portal is retained by the author(s) and / or other copyright owners and it is a condition of accessing these publications that users recognise and abide by the legal requirements associated with these rights.

Take down policy

The Research Portal is Queen's institutional repository that provides access to Queen's research output. Every effort has been made to ensure that content in the Research Portal does not infringe any person's rights, or applicable UK laws. If you discover content in the Research Portal that you believe breaches copyright or violates any law, please contact openaccess@qub.ac.uk. 


\title{
Attainment grouping as self-fulfilling prophesy? A mixed methods exploration of self confidence and set level among Year 7 students
}

Becky Francis ${ }^{a}$, Paul Connolly ${ }^{b}$, Louise Archer ${ }^{a}$, Jeremy Hodgen ${ }^{a}$, Anna Mazenod ${ }^{a}$, David Pepper ${ }^{c}$, Seaneen Sloan ${ }^{b}$, Becky Taylor ${ }^{\mathrm{a}}$, Antonina Tereshchenko ${ }^{\mathrm{a}}$

${ }^{a}$ UCL Institute of Education, London, UK;

${ }^{b}$ Faculty of Arts, Humanities and Social Sciences, Queen's University Belfast, Belfast, UK;

'School of Education, Communication and Society, King's College London, London, UK

\begin{abstract}
Within-school segregation of pupils by attainment remains prevalent, despite evidence that these practices detrimentally impact outcomes for those in low attainment groups. This article explores the hypothesis that 'ability grouping' by setting impacts pupil self-confidence, precipitating a selffulfilling prophecy. Survey data from 11,546 11/12 year old pupils in 'ability sets', and individual interviews and focus groups with 66 pupils, are drawn upon to explore this hypothesis. We find a significant correlation between perceived set placement and self-confidence in the set subject. More importantly, we also find a correlation between set placement and general self-confidence in learning. Pupils' qualitative responses illustrate how setting can promote self-fulfilling prophecy, and worrying evidence of internalisation of 'ability' labels among pupils.
\end{abstract}

\section{Background}

Segregation of students by attainment remains a controversial area. Despite an extensive, longstanding, international body of research questioning the value of grouping students by 'ability', the approach remains prevalent in many international contexts; whether via institutional segregation, or via within-school practices of tracking (referred to as 'streaming' in the UK), setting, or within-class groups organised on the basis of attainment (Francis et al, 2017).

The research on 'ability grouping' is diverse, complex, and not without issues. For example, different attainment grouping practices are frequently conflated within different pieces of research or metaanalyses, and sometimes there is a lack of clarity on the nature of the practices analysed (Dracup, 2014). Moreover, as we have observed elsewhere, while it has been long established that there is no statistically-significant beneficial effect of attainment grouping overall (see, e.g. Slavin, 1990; Ireson \& Hallam, 2001; Boaler et al, 2000; Kutnick et al, 2005; EEF, 2016), with a marginal benefit to high attainers balanced by a more significant detrimental impact for low attainers (Wiliam and Boaler, 
2001), there has been little effort to disaggregate potential explanations for these findings (Francis et al, 2017). There also continues to be controversy concerning the impact of student grouping practices on the highest attainers, where evidence suggests these students benefit from extension (Steenbergen-Hu et al, 2016). Again, the research on facilitating these exceptional students has often been unhelpfully conflated with that on grouping practices and pupil outcomes more broadly (EEF, 2016; Steenbergen-Hu et al, 2016).

Nevertheless, the longstanding finding of a negative impact of attainment grouping on those young people in low attainment groups (see e.g. Slavin, 1990; Kutnick et al, 2005; Higgins et al, 2015) comprises a significant issue for social justice, especially given that young people from low socioeconomic backgrounds tend to be over-represented in these groups (Jackson, 1964; Kutnick et al, 2005; Dunne et al, 2007; Taylor et al, 2017). In this sense, the research implies that many young people in low attainment groups face a double disadvantage (Francis et al, 2017): they begin schooling with disadvantaged starting point due to their low socio-economic status, but are then additionally subject to educational practices that constrain, rather than accelerate, progress. This is especially significant within an English context given the scale of the practice of attainment grouping in England (Hallam et al, 2003). In secondary schooling (high school) the vast majority of schools practice setting, wherein pupils are segregated by attainment for particular subjects, and a smaller portion also apply 'streaming' (tracking) where pupils are banded by prior attainment and stay in these same groups for the majority of curriculum subjects.

Elsewhere we have set out the seven different explanations for the poorer progress for those in low 'ability' groups evidenced in the literature on attainment grouping (Francis et al, 2017). Two of the potential explanations are: pupil perception and experiences of attainment grouping, and the impact on their learner identities; and (relatedly) self-fulfilling prophesy. Here the label of 'low achiever' that is somewhat explicit in the act of placement in a low attainment group precipitates a set of assumptions, behaviours and educational offers that serve to ensure that low attainment is further established. These latter include particular pedagogic and curriculum offers, reflective of lower expectations, that tend to be applied to pupils in low attainment groups (see e.g. Ireson \& Hallam, 2001; Ireson et al, 2005; Dunne et al, 2007; Rubie-Davies, 2007), but also particular behaviours and dis/associations in the young people concerned as they respond to having been labelled 'low ability'. Conversely, there is also evidence of a set of favourable practices that are precipitated by placement in high attainment groups, including allocation of subject-specialist teachers, application of high expectations and related pedagogy and resources, and so on (Finley, 1984; Ireson \& Hallam, 2001; Kelly, 2004). 


\subsection{Research on the impact of attainment grouping on self-confidence}

It has been shown that self-perception ii impacts young people's educational outcomes, and that this can be related to attainment grouping. For example, Linchevski and Kutscher (1998) showed that young people with similar prior attainment levels performed better when placed in higher attainment classes than in lower attainment classes. Of course, this could possibly be explained by teacher quality and/or curriculum offer targeted at the different group (these are also identified as tending to differ depending on attainment group level; Ireson \& Hallam, 2001; Kelly, 2004). But it seems likely that the labelling of young people according to placement in attainment groups also impacted performance. Carol Dwek's (2006) work on 'mindset' also highlights the import of student self-perception for learning, and the detrimental implication of messages that 'ability' is fixed.

There has been a range of international work exploring the impact of different conceptions of students' sense of self on their learning outcomes. This populous field includes attention to the constructs of self-confidence, self-esteem, self-concept, and/or self-efficacy. These constructs are all somewhat distinct, and reflect different disciplinary perspectives and trajectories, but are not always distinguished or applied consistently. Sociological work tends to explore notions of self-confidence and esteem. For example, researching in Flanders, Houtte et al (2012) found that students on 'academic track' have significantly higher self-esteem than students on 'vocational track'. They found that these discrepancies for self-esteem were greater for students in multilateral schools than in categorial schools, leading Houtte et al (2012) to speculate that in schools that contain both tracks academic students may compare themselves with the vocational track students, resulting in a higher awareness of status differences and consequently higher self-esteem. Addressing self-confidence, Brown et al (2008) found that lack of self-confidence was among reasons that students were deterred from pursuing Maths at post-16.

Psychologists have frequently applied the construct of self-concept. Ireson and Hallam (2009) found that students' academic self-concept was correlated with attainment grouping across the three subject areas they investigated, with those in the top attainment groups having higher self-concept than those in low attainment groups. However, this correlation with respective attainment group did not extend to general self-concept. This contrasted to findings from a prior study which found that students in schools using 'moderate levels of setting' had higher general self-concept; and that setting in English tended to lower the self-concepts of the higher attaining pupils and to raise the self-concepts of lower attaining pupils (Ireson \& Hallam, 2001). In their Singaporean study of 
streaming (tracking), Liem et al (2015) found that between-stream differences in academic selfconcepts were negligible, where in the same national context Liu et al (2005) found that streaming appeared to have a short-term negative impact on lower-'ability' stream students' academic selfconcept (albeit they also found this relationship reduced over a three year period). Belfi et al's (2012) literature review surprisingly concluded that 'ability' grouping is beneficial for the academic self-concept of lower attaining students. Kulik and Kulik's (1982) meta-analysis found no relationship between tracking and self-concept. However, somewhat parallel with the sociological findings of Houtte et al (2012), Marsh (1984) draws attention to the relativistic nature of self-concept, arguing that it depends on some frame of reference, and that 'ability' grouping is likely to have 'substantial effects on self-concepts within different ability groupings' (p. 799): what he refers to as the 'Big-fishlittle-pond effect'. Hence Marsh (2008) later showed that equally 'able' students have lower academic self concept when attending schools where average attainment levels are high, than when attending schools where peer attainment is low. This idea has generated a great deal of interest among self-concept researchers (see e.g. Chmielewski et al, 2013; Preckel et al, 2010; Suk Wai Wong \& Watkins, 2001).

Hence the prior literature utilises a variety of distinct constructs around student self-perception in relation to attainment grouping, and presents a range of findings, with the tentative trends being that attainment grouping tends to have some impact on student self-perception, and that relationality (i.e. to what students are comparing themselves) has a bearing on this. However, the research has been far from conclusive, and has tended to have a quantitative focus that has not attended closely to students' articulated experiences in explaining these patterns.

Identifying primarily with the sociological literature, we have applied an inclusive construct of selfconfidence within our study, and have also designed survey measures and items to explore students' liking for school and for particular curriculum subjects. Within this article we draw on two different theoretical traditions. The first is the sociological constructs of self-fulfilling prophecy (Merton, 1948) and labelling (Lemert, 1951; Becker, 1963). These theories suggest that the application of a label to an individual or group precipitates social actions and behaviours which result in the original label (prophecy) coming true (self-fulfilling). Applying these concepts to attainment grouping, we might assume that designation to a group ascribed either high or low attaining would precipitate and perpetuate understandings on the part of the individual student and others that their 'ability' in the subject concerned accords with this designated label (especially given that such segregation is often overtly branded 'ability grouping'). With consequences for the students' self-confidence and 
subsequent expectations and behaviours; and those applied to them by teachers, peers, and so on (Jackson, 1964); potentially resulting in the prophecy of 'high' or 'low attainer' being fulfilled.

The second theoretical perspective drawn upon is psycho-social theory (Hollway \& Jefferson, 2000); specifically psycho-social theoretical application of Klein's $(1952 ; 1963)$ object relations theoretical concepts of defendedness and projection. Klein believed that aspects of the polarised emotional world of the infant, where good and bad, the idealised and the demonised, are kept apart, manifest in a 'splitting' off of reviled or demonised feelings from the self onto others, via 'projection'. And that these 'schizoid' practices of splitting are to some extent maintained in later life, enabling us to defensively project intolerable feelings of anxiety, hate or destructiveness onto other objects, individuals or groups. Various researchers have applied elements of this perspective to aspects of education; most notably Helen Lucey and her various collaborators (Lucey \& Reay, 2002; Lucey et al, 2006; Lucey, 2010). In this article we draw on psychosocial theory to explore students' constructions of attainment grouping.

Hence building on debates in the prior literature, this paper seeks to make a significant contribution to the field by drawing on a large-scale dataset to analyse whether young people's self confidence in their educational capabilities differs depending on the attainment 'set' ${ }^{\prime i i}$ in which they are placed. Particularly, it seeks to identify whether or not set level relates to self-confidence in relation to the curriculum subjects concerned, and in relation to learning more generally. Qualitative data analysis is used to explore the experiences reported by students that underpin the quantitative trends identified, with the theoretical constructs elaborated above being applied to shed light on students' articulations.

\section{Methodology}

The data discussed here draws from a large scale mixed-methods project 'Best Practice in Grouping Students', funded by the Education Endowment Foundation. The project seeks to address prior gaps in the literature, by exploring: whether practice in settingiv that remediates some of the problematic practices identified in the literature as affecting those in low groups might improve young people's progress; what comprises good practice in mixed attainment pedagogy; and whether outcomes and experiences are better for young people in setted or mixed attainment groups. It includes the following methods:

- Two two-year interventions, one tested by a fully-powered RCT ('Best Practice in Setting') and one constituted as a randomised feasibility study ('Best Practice in Mixed Attainment 
Grouping' $)^{v}$, examining impact or otherwise of practice in grouping students in Year 7 and Year 8 based on research evidence.

- Surveys of pupils and teachers involved in the study

Qualitative individual interviews with students and teachers, and focus groups with students. The interventions and research are undertaken in 139 secondary schools in England (divided into intervention or control groups), and involve instigating work with and tracking student cohorts from the beginning of Year 7 (11-12 years old) to the end of Year 8 (12-13 years old), focusing on their experiences and outcomes in English and Maths. English and maths were selected as the foci because: a) they are two subjects given longstanding priority in the national curriculum and within school performance indicators; and b) they represent diversity in content and pedagogy.

The data reported here are generated by surveys and interviews. The quantitative data for this article is drawn exclusively from the Best Practice in Setting aspect of the study (ie, all schools from which the data is collected are practicing setting), as our focus is on relative levels of self-confidence for pupils placed in different set levels. The survey data for the broader study comprises questionnaire responses from 12,997 Year 7 pupils in 96 secondary schools across England. The survey was offered to all schools in the study, and 96 out of 139 participated and provided data, a response rate of $69 \%$. Of the 96 schools providing pupil responses, 77 apply setting in maths in Year 7, and 39 apply setting in English (some of these schools from the control group additionally apply tracking, or 'streaming' as it is referred to in the UK). In our quantitative analysis in this article we attend to the responses from 11,546 Year 7 students in 86 schools participating in the 'Best Practice in Setting' study (i.e. those experiencing setting). Summary characteristics for the sample are provided in Table 1. Social class background was analysed via questions concerning parental/carer occupation, with categorisation according to the highest status occupation between parents.

Following this analysis (and given longstanding difficulties in judging the nature and content of some occupations), the tiered occupations were further categorised as 'professional/managerial, intermediate, and semi/unskilled'.

Table 1. Summary Characteristics of the Sample

\begin{tabular}{llrc}
\hline Variable & Categories & Frequency & Valid Percent* \\
\hline Gender & Males & 6,095 & 52,8 \\
& Females & 5,451 & 47.2 \\
\cline { 2 - 4 } & Total & 11,546 & 100.0 \\
\hline Household Occupation & Professional/Managerial & 4,938 & 48.4 \\
& Intermediate & 3,541 & 34.7 \\
& Semi-Skilled/Unskilled Manual & 1,721 & 16.9 \\
& Missing & 1,346 & \\
\cline { 2 - 4 } & Total & 11,546 & 100.0 \\
\hline
\end{tabular}




\begin{tabular}{llrr}
\hline Ethnicity & White & 8,571 & 74.3 \\
& Asian & 1,052 & 9.1 \\
& Black & 698 & 6.1 \\
& Mixed & 991 & 8.6 \\
& Other & 226 & 2.0 \\
& Missing & 8 & \\
\cline { 2 - 4 } Set Allocation (Maths) & Total & 11,546 & 100.0 \\
& Top Set & 3,264 & 31.8 \\
& Middle Sets & 5,663 & 55.1 \\
& Bottom Set & 1,354 & 13.2 \\
& Not Relevant ** & 1,265 & \\
\cline { 2 - 4 } Set Allocation (English) & Total & 11,546 & 100.0 \\
& Top Set & 1,575 & 30.8 \\
& Middle Sets & 2,798 & 54.7 \\
& Bottom Set & 745 & 15.3 \\
& Not Relevant** & 6,428 & \\
\cline { 2 - 4 } & Total & 11,546 & 100.0 \\
\hline
\end{tabular}

*Percentages may not sum exactly to 100.0 due to rounding.

**These cases are due to students who were only allocated to sets for one subject. Of the total sample of 11,546 , there were 6,428 students who were set for English and maths. As these figures indicate, 1,265 were only allocated to sets in English and 6,428 were only allocated to sets in maths.

The questionnaires were administered in Autumn 2015, soon after those pupils being set had arrived at secondary school and had been placed in attainment groups. As such, the responses were provided when any pupils being set knew their set group, but had not had long experience of it; and before they would have experienced pedagogic impact of the study intervention. We shall carry out a further survey round when these same pupils are reaching the end of Year 8 , to explore the impact of two years of experience of this grouping on their self-confidence, and school and subject identification.

The questionnaire completion process was administered by school teachers, following instructions on administration protocols. Classes completed the questionnaires online, via Survey Monkey. The questionnaires took approximately half an hour to complete, and included questions on perceptions of maths and English, liking for school, and perceptions of attainment grouping. They included various self-confidence measures constructed of a range of items, addressing self confidence at maths and English and general self-confidence in learning. Questionnaire items were partly drawn from Ireson and Hallam (2009) with additional of our own, and had been extensively piloted with students in the pilot year of our project. Nevertheless, is was notable that some teachers reported some students taking a long time to complete the questionnaire and/or struggling to complete it, highlighting the methodological challenge to accommodate a genuinely diverse range of prior attainment within a large sample. 
The main foci for the quantitative analysis to follow are three measures of self-confidence: selfconfidence in English, self-confidence in maths and general self-confidence in learning. The items used for each are detailed in Table 2. These measures have been adapted from the self-confidence scales used in the international TIMSS and PIRLS studies (Martin \& Mullis, 2012). All three measures were found to be unidimensional and thus valid and also, as shown, were found to be reliable. With regard to set levels, schools varied in relation to the number of sets they used, from two to 10 , with most falling between 3 and 5 (intervention schools in the setting trial had been specifically asked to cap set level number at maximum 4). For the purposes of this current analysis, students were coded into three groups for English and maths respectively in each school: those in the very top set; those in the middle set(s); and those in the very bottom set. Thus, for a school with four sets, the top set was coded ' 1 ', the middle two sets coded ' 2 ' and the bottom set coded ' 3 '. Similarly, for a school with five sets, the top set was coded ' 1 ', the middle three coded ' 2 ' and the bottom set coded ' 3 '. The breakdowns of the sample by these three categories for English and maths are also shown in Table 1.

Table 2. Scales for Self-Confidence in English/Maths and General Self-Confidence

\begin{tabular}{ll}
\hline Scale and Items & $\begin{array}{l}\text { Reliability and Summary Statistics } \\
\text { of Scales* }\end{array}$ \\
\hline Self-Confidence in English/Maths: & Maths Scale: \\
- "Work in English/maths is easy for me" & Alpha $=0.88$ \\
- "I am not very good at English/maths" & Mean = 27.22 (SD = 5.70) \\
- "English/maths is one of my best subjects" & English Scale: \\
- "I hate English/maths" & \\
- "I ge well at English/maths" & Alpha = 0.86 \\
- "I learn things quickly in English/maths lessons" & Mean = 26.54 (SD = 5.88) \\
& \\
\hline General Self-Confidence in Learning: & \\
- "I learn quickly" & Alpha = 0.84 \\
- "Most things I do, I do well" & Mean = 25.22 (SD = 3.94) \\
- "I am proud of my achievements at school" & \\
- "I can do things as well as most people" & \\
- "If I really try I can do almost anything I want to" & \\
- "I am confident in my abilities" & \\
\hline
\end{tabular}

The data were analysed by fitting a series of multilevel models with students (level 1 ) clustered within individual subject sets (level 2) and then within schools (level 3). In each model, dummy variables representing the three categories of set level (top, middle and bottom) were included along with a series of other covariates representing gender, family occupation, ethnicity and total number of sets within the school. The models were then used to estimate the adjusted mean self- 
confidence scores for students in the three set levels, controlling for these covariates. Practically, this was done by adding in a series of values to the model. These values consisted of either: the relevant values of the dummy variables for the set levels (i.e. either ' 0 ' or ' 1 '); or the mean scores for each of the other covariates included in the model; or ' 1 ' for the constant. The mean self-confidence score was then calculated by adding together the products of each of the cofficients in the model with its associated value. The standard deviations for each of the mean scores estimated were calculated using the raw data and the size of each sub-sample represented the total number in each category for whom there were full data (and thus whose data were included in the model).

In addition, qualitative interview data drawn on here was generated in the pilot phase of research, with six schools based in London and one in the Midlands. This includes 26 individual semistructured interviews and nine focus groups with Year 7 students, and one focus group with Year 8 students (66 students in total). (We are presently extending our qualitative research to a national sample: this work is ongoing). Individual interviews ranged between 10-30 minutes in length. However, during the pilot we felt concerned that students with low prior attainment were not tending to elaborate their answers in these interviews, and that perhaps asking about their attainment grouping experiences (even with carefully-prepared questions intended to be sensitive) might be experienced as painful by students. We noticed that for these students, focus groups with peers from the same set appeared to offer a more facilitative environment where perhaps parity of attainment group placement served to dissolve issues that caused reticence in individual interviews. Interviews were fully transcribed and thematically organised via NVivo. Data was then subject to the analytical lenses described above, by Author 1 . This analysis was assessed against the original transcripts by two other members of the project team.

Confidentiality was foregrounded in both questionnaires and interviews, and all school and student names used in this article are pseudonyms (student details, and where relevant set level for English and maths respectively, are recorded in each case). The project was approved by UCL Institute of Education's ethics committee. As noted above, there are however issues of sensitivity in questioning young people about their attainment grouping - questions could potentially cause embarrassment for and/or unintentionally problematize those students in low attainment groups. We have sought to be attuned to these issues and respectful of students in our formulation of questions and methods, and to carefully pilot questions and be responsive to issues arising.

\section{Self-confidence and perceived set level in English and maths}


It is important to point out that here and throughout, that our analysis is based on students' selfreports (perceptions). We have also collected data from schools on their reported grouping practice. Students' perceptions of grouping are however central to this article, as it is these that are hypothesised to impact on self-confidence and/or identification with particular subjects.

To provide some initial feel for the nature and extent of the relationship between set allocation and self-confidence, descriptive statistics from one of the items ("I am not very good at English/maths") are summarised in Table 3. As can be seen, for both subjects, there is a clear relationship between set allocation and self-confidence in that subject. Those in the bottom sets, for example, are about three times more likely to agree with the statement compared to those in the top sets. However, whilst there is a clear association between set allocation and self-confidence, it is also worth noting that the relationship is far from perfect. As can also be seen, nearly half of those in the bottom sets in both subjects, for example, tend to disagree with this statement. This should serve as a warning against assuming from these overall tendencies that all students in bottom sets lack self-confidence or, indeed, that all students in top sets have high self-confidence.

Table 3. Students' self-assessment of their ability in maths and English

\begin{tabular}{llrlrlrl}
\hline Statement & $\begin{array}{l}\text { Allocated Set in } \\
\text { Maths or English }\end{array}$ & $\begin{array}{c}\text { Agree or } \\
\text { Strongly Agree }\end{array}$ & & & Undecided & \multicolumn{2}{c}{$\begin{array}{c}\text { Disagree or } \\
\text { Strongly Disagree }\end{array}$} \\
& Mop Set & 329 & $10.5 \%$ & 239 & $24.1 \%$ & 2,574 & $81.9 \%$ \\
\hline $\begin{array}{l}\text { "I am not very good at } \\
\text { maths" }\end{array}$ & Middle Set & 1,292 & $24.1 \%$ & 892 & $16.6 \%$ & 3,180 & $59.3 \%$ \\
(n=9,773) & Bottom Set & 436 & $34.4 \%$ & 237 & $18.7 \%$ & 594 & $46.9 \%$ \\
& Top Set & 210 & $13.7 \%$ & 176 & $11.5 \%$ & 1,146 & $74.8 \%$ \\
\hline $\begin{array}{l}\text { "I am not very good at } \\
\text { English" }\end{array}$ & Middle Set & 736 & $27.6 \%$ & 481 & $18.0 \%$ & 1,452 & $54.4 \%$ \\
(n=4,922) & Bottom Set & 242 & $33.6 \%$ & 147 & $20.4 \%$ & 332 & $46.1 \%$ \\
& & & & & & & \\
\hline
\end{tabular}

This relationship was more formally analysed using multilevel models as described above. Full details of all the models fitted for the present analysis are provided in Table 4 (Models A and B). Table 4 also includes details of the actual number of observations for each model. These can be compared with the total initial samples for those who have been set for maths $(n=10,281)$ and that who have been set for English $(n=5,118)$ as detailed earlier in Table 1. With these initial figures in mind, it can be seen that the models are based on respectable response rates of between $77 \%$ and $85 \%$. 
As described in the previous section, these models were used to calculate the adjusted mean scores in self-confidence. The adjusted mean scores in self-confidence in maths and English by perceived set allocation are summarised in Table 5. It can be seen that there is a clear relationship, with levels of self-confidence in the subjects increasing as students perceive themselves to be in higher sets. The relationship appears to be a little stronger in maths, with the mean scores for those in the top sets being a little over two thirds of a standard deviation higher than those in the bottom (Hedges' $g$ $=0.71 ; 95 \% \mathrm{Cl}: 0.64,0.78)$, whereas it is half a standard deviation in English ( $g=0.51 ; 95 \% \mathrm{Cl}: 0.41$, 0.61). Also, and as can be seen, the gap is notably larger between those in the top and middle sets compared to those in the middle and bottom sets. This pattern is also illustrated in Figure 1.

Table 4. Multilevel models used to compare mean scores in self confidence by set level, controlling for number of sets in school, family occupation, ethnicity and gender

\begin{tabular}{|c|c|c|c|c|}
\hline \multirow[t]{2}{*}{$\begin{array}{l}\text { Independent Variables in } \\
\text { the Model }\end{array}$} & \multicolumn{2}{|c|}{$\begin{array}{l}\text { Dependent Variable }=\text { Self- } \\
\text { Confidence in Maths or English }\end{array}$} & \multicolumn{2}{|c|}{$\begin{array}{c}\text { Dependent Variable = General } \\
\text { Self-Confidence }\end{array}$} \\
\hline & $\begin{array}{c}\text { Maths } \\
\text { (Model A*) }\end{array}$ & $\begin{array}{c}\text { English } \\
\text { (Model B*) }\end{array}$ & $\begin{array}{c}\text { Maths } \\
\text { (Model C*) }\end{array}$ & $\begin{array}{c}\text { English } \\
\text { (Model D*) }\end{array}$ \\
\hline Number of Observations & 8,556 & 8,766 & 3,948 & 3,965 \\
\hline \multicolumn{5}{|l|}{ Set Allocation } \\
\hline Top & $2.821(.206)$ & $2.151(.218)$ & & $.935(.136)$ \\
\hline Middle (Ref Cat) & & & $.977(.123)$ & \\
\hline Bottom & $-.743(.256)$ & $-.675(.300)$ & & $-.771(.189)$ \\
\hline No. of Sets in School & $.218(.101)$ & $-.009(.122)$ & & $.053(.073)$ \\
\hline \multicolumn{5}{|l|}{ Family Occupation } \\
\hline Higher & $.398(.163)$ & $.803(.245)$ & $-1.019(.158)$ & $.849(.157)$ \\
\hline $\begin{array}{l}\text { Intermediate } \\
\text { Lower (Ref Cat) }\end{array}$ & $-.049(.168)$ & $-.049(.253)$ & $-.034(.069)$ & $.294(.162)$ \\
\hline \multicolumn{5}{|l|}{ Ethnicity } \\
\hline White & $-.342(.193)$ & $-.414(.305)$ & & $-.217(.195)$ \\
\hline Asian & $1.262(.272)$ & $.558(.414)$ & .745 (.110) & $.317(.264)$ \\
\hline $\begin{array}{l}\text { Black } \\
\text { Other or Mixed (Ref Cat) }\end{array}$ & $1.027(.299)$ & $.795(.465)$ & . $252(.114)$ & $.009(.298)$ \\
\hline \multicolumn{5}{|l|}{ Gender } \\
\hline Male & $1.229(.117)$ & $-1.195(.180)$ & $-.191(.131)$ & $.045(.116)$ \\
\hline Female (Ref Cat) & & & $.455(.184)$ & \\
\hline \multirow[t]{3}{*}{ Constant } & $24.852(.525)$ & $26.623(.676)$ & $.487(.202)$ & $24.568(.413)$ \\
\hline & & & $-.139(.079)$ & \\
\hline & & & $25.044(.355)$ & \\
\hline \multicolumn{5}{|l|}{ Variance } \\
\hline School Level & $.362(.164)$ & $1.026(.388)$ & $.226(.078)$ & $.379(.140)$ \\
\hline Set Level & $1.063(.204)$ & $.746(.285)$ & $.306(.077)$ & $.167(.088)$ \\
\hline Student Level & $26.441(.411)$ & 29.775 & $12.489(.192)$ & $12.365(.283)$ \\
\hline$-2 \mathrm{LL}$ & 52543.9 & 24715.1 & 47211.6 & 21310.6 \\
\hline
\end{tabular}

*Estimated coefficients with associated standard errors in parentheses 
Table 5. Adjusted mean scores in self-confidence in maths and English by perceived set allocation in those subjects in school*

\begin{tabular}{lccccccc}
\hline Sets & \multicolumn{3}{c}{ Maths } & & \multicolumn{3}{c}{ English } \\
\cline { 2 - 4 } \cline { 7 - 8 } & Mean & SD & $\mathrm{N}$ & & Mean & SD & $\mathrm{N}$ \\
\hline Top Sets & 28.40 & 4.72 & 2,930 & & 28.23 & 5.29 & 1,350 \\
Middle Sets & 25.58 & 5.62 & 4,559 & & 26.08 & 5.80 & 2,055 \\
Bottom Sets & 24.84 & 5.81 & 1,067 & & 25.41 & 6.02 & 543 \\
\hline
\end{tabular}

*Adjusted mean scores calculated using three-level multilevel models and controlling for gender, family occupational background, ethnicity and total number of sets in each school.

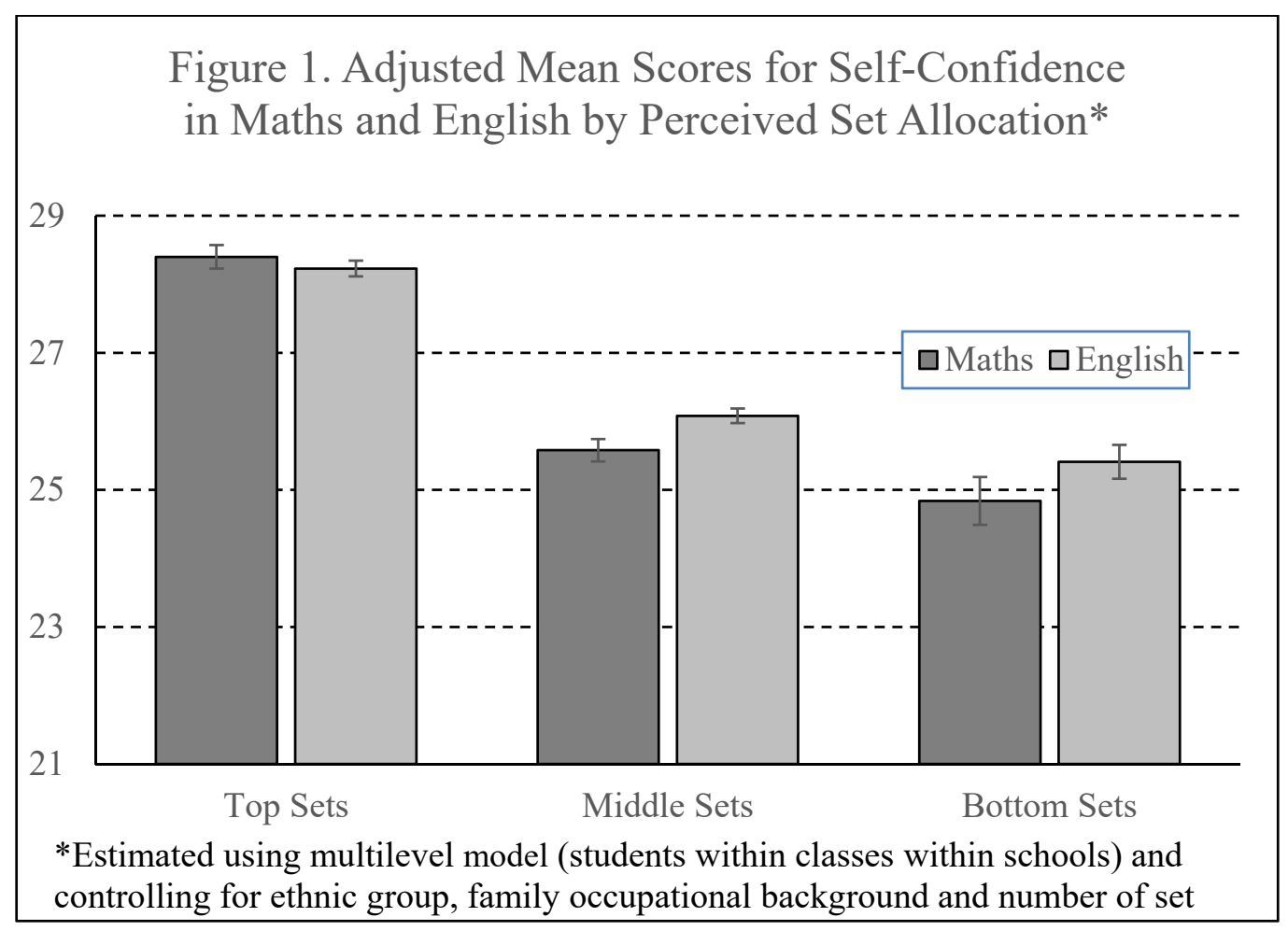

\section{General Self-confidence in learning by perceived set level in English and maths}

Given the findings from previous research summarised earlier, we were also interested in examining whether this relationship between self-confidence and perceived set allocation was largely restricted to self-confidence in the particular curriculum subject wherein pupils were set, or whether it was also reflected in the students more general self-confidence in relation to learning. To answer this question, the above analysis was repeated using the broader measure of general self-confidence in learning. Full details of the multilevel models fitted are provided in Table 4 (Models $C$ and $D$ ) and the mean scores estimated from these models are reported in Table 6 and illustrated in Figure 2. It can be seen that there is also a clear relationship between perceived set allocation and general levels of self-confidence that is very similar for maths and English. This new finding is important as it 
demonstrates that the impact of setting on self-confidence extends beyond the subjects in which setting applies, to pupils' self-confidence in learning more generally. Again, the size of the gap in mean scores from top to bottom sets is slightly larger for maths ( $\mathrm{g}=0.57 ; 95 \% \mathrm{Cl}: 0.49,0.64$ ) compared to English ( $g=0.48 ; 95 \% \mathrm{CU}: 0.38,0.58$ ). However, it is also notable that in contrast to the earlier findings, the gaps between top and middle, and also between middle and bottom, appear to be broadly similar.

Table 6. Adjusted mean scores in general self-confidence by perceived set allocation in maths and English in school*

\begin{tabular}{lccccccc}
\hline Sets & \multicolumn{3}{c}{ Maths Sets } & & \multicolumn{3}{c}{ English Sets } \\
\cline { 2 - 4 } \cline { 7 - 8 } & Mean & SD & N & & Mean & SD & $N$ \\
\hline Top Sets & 26.17 & 3.24 & 2,988 & & 26.15 & 3.34 & 1,354 \\
Middle Sets & 25.20 & 3.71 & 4,682 & & 25.22 & 3.70 & 2,069 \\
Bottom Sets & 24.18 & 4.19 & 1,096 & & 24.45 & 3.93 & 542 \\
\hline
\end{tabular}

*Adjusted mean scores calculated using three-level multilevel models and controlling for gender, family occupational background, ethnicity and total number of sets in each school.

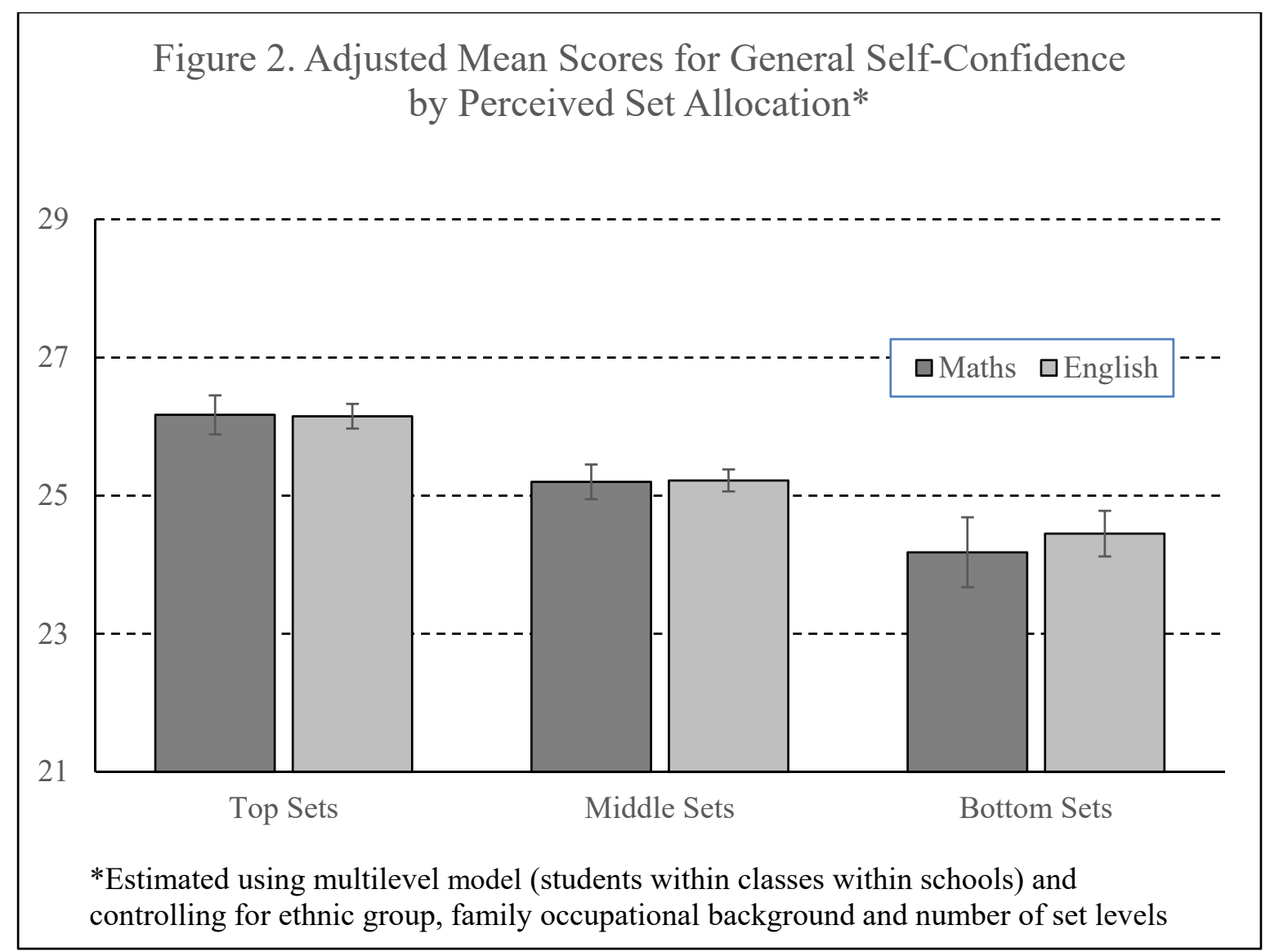

To summarize, we see a clear relationship between set level and self confidence in both the setted subjects concerned and in learning more broadly, compounding the implication in our findings that 
the labelling associated with allocation to sets triggers a self-fulfilling prophecy in relation to pupils' perceptions of the subject concerned, and their relationship to it. For those allocated to high attainment sets, this may cement their confidence and provoke positive associations with the subject; whereas for those in lower sets the reverse is the case. This finding is of particular concern, as it is long-established that those in low attainment groups - i.e. subject to negative labelling and hence prey to negative self-fulfilling prophesy - over-represent students from low social class backgrounds (and from certain minority ethnic groups, such as African-Caribbean heritage boys), hence potentially explaining disengagement and the gap in progress and outcomes for these groups. We return to this point in the Discussion section.

We turn now to the qualitative data, exploring students' own constructions and explanations in relation to these patterns concerning set level and self-confidence.

\section{Labelling and Self-fulfilling prophecy}

Many students, both those that experienced sets and those that were presently in mixed-attainment classes, articulated the labelling element implicit in the act of setting - the designation of a set attainment group as a label of level of ability. As Fred (sets 1, White British, middle class, School Z) observes, "We can try to hide it, but it is blatantly saying, 'You are less intelligent than this person.' So, I think some people definitely feel a bit miffed about that." Likewise, students highlighted the impact of the label in precipitating self-fulfilling prophecy in those concerned:

Yes, some people think if they're in a lower set they're not good at anything. (Kenneth, sets 1 and 2, African heritage, middle SES, School C).

Well, it does sound really disheartening and really disappointing if you're put into a lower group when maybe in your old school you were in a higher group and it makes you upset and a lot less excited to do the work, and stuff. If you're in the top group, you'd be like, 'Yeah! I want to do this work, it will be hard and fun.' But then when you're in the lower groups, you're like, 'I'm in the lower group. It will be rubbish and boring because I'm stupid' or whatever. (Henry, mixed attainment class, White British, middle SES, School E).

What is also interesting is that this labelling is not seen as ascribing present attainment, but rather, fixed ability. For example, James (sets 2 and 4, White British, low SES, School B) explains that, "It 
affects us because it makes you feel either you are cleverer or have better abilities, or not very good abilities...or not very good, basically", and confesses that "I think like that sometimes".

As these quotes imply, an ingredient in this perceived self-fulfilling prophecy is the impact on selfconfidence precipitated by the label. In the following extract from a mixed attainment class focus group (School E), the students make this point explicitly:

Alice: [...] if you're in the same attainment group then if you're all low level but you know there's a higher group than you, then you might feel less confident, like you're not doing as well as you should.

Iris: $\quad[. .$.$] I think it can knock their confidence [..]. So if there was a way that they$ could stop people from knowing which was top and bottom, then it would be easier, because then they wouldn't know whether they were moving up or down and they could still feel confident.

Hilda: Definitely.

Camilla: Definitely

Henry: Yes.

Camilla: Because it can really lower your self-esteem. If you think you're a lot better than you are and then you're put in the bottom group for something and you'd be like... it might upset you, it might make you feel angry and it would definitely affect the way you thought of school.

The group's further discussion powerfully evokes other potential debilitating and Othering effects of placement in a low attainment group:

Chris: Especially if all your friends in the higher group and then you're in the lower group and they're all talking about, "What did you get on this test?" and you did it on a different test.

Camilla: And you didn't do very well.

Chris: Yes, you didn't do that well, or something, you feel a bit left out.

Camilla: You might feel a bit 'Special'. A bit disabled, a bit Special Needs, stuff like that.

Hilda: Because last year I was, well all the way through my primary school, I was always in the bottom set for spelling, I've never really, since then, I've never really, if my mum goes, 'You need to practise your spelling' I always feel I never want to practise it because I always think that I'm always going to get it wrong and I'm 
never going to get it right because I'm really bad at spelling and I'll always be really bad at spelling. I don't know, in some ways it would make you want to try harder to get into the higher set but, for me, I don't want to try because it would just be... I'd feel like -

Chris: Humiliation.

Hilda: - then I'll get it wrong and I'd be really humiliated myself if I get it wrong. So I don't really know, but that's how I feel about it.

This short exchange contains multiple emotionally-laden and difficult themes. The practical segregationist consequences of setting on pupil social relations is effectively evoked in Chris' exemplar of the taking of different tests, and the socially-excluding effects of such distinctions ('you feel a bit left out'), in addition to the impact on self-esteem implicated in the not doing 'that well' and feeling 'a bit Special'. The allusion to Special Educational Needs ${ }^{\mathrm{vi}}$ and the positioning of this label as denigrated and 'different' reminds us of another label operating in schools, and the way in which young people interpolated by this label frequently continue to be constructed as Other and deficit in spite of their ostensible 'inclusion' within state education (see Dytham, 2016). In this way, its application also effectively illustrates the denigrated, abject status and implication for social relationships and individual psyches bound up in the designation of 'low ability group'. In psychosocial terms, we may see the projected identities of different set groups as examples of splitting, where deficiencies are cast out and projected onto denigrated objects - in this case, low sets and those ascribed to them. The social and psychic consequences of academic 'failure' are reinforced by Chris and Hilda's use of the word 'humiliation' to articulate impotence and shame. Again, Hilda's movingly frank articulation of her struggles with spelling provide a visceral illustration of selffulfilling prophecy in action.

The importance for pupils of respect - being respected, and self-respect ${ }^{\text {vii }}$ - arose frequently, with placement in a low set being constructed as undermining this (see also Lucey and Reay [2002], for similar findings in relation to placement in schools perceived poor quality). For example, Tanvi (mixed attainment class, South Asian, SES unknown, School F) imagines being "stuck in the lowest group", reflecting, "You'd be like, 'There's so many people in the high levels, and I'm just stuck here. I feel the odd one out, and I wish I was a high level, because then, my parents would be proud of me, as well.'" This theme is extended by Salima who asserts that, 
in my primary school I didn't like my maths class, because the people that were in the higher group, Miss, she treated them with more respect and stuff. The people in the lower group, she thought they needed a lot of help and stuff. She didn't really treat us like the way she treated the higher tables and stuff.

As one of us has observed elsewhere (Francis, 2000), adults often forget the way that time is experienced differently by children; how days and years at school stretch out for young people, who have no choice but to attend - and the consequently heightened import of social relations and status within school for their daily lives. Status with peers, and self-pride, are vital defences, yet may be damaged or bolstered by setting, depending on set designation.

A further mixed attainment class focus group compared their present experience with their previous experiences of setting at primary school:

Rani: I don't like sets and stuff. I like being with my class.

Navya: Yeah.

I: Why's that?

Anaya: It feels like they're [school/teachers] picking on you.

Riya: So, yeah, it feels kind of weird. It's like the teachers don't like you because they think that you're dumb, and then the other people are smarter than you.

Salima: Yeah.

Riya: And, it makes you feel a bit weird. That's why I wasn't really confident when I was in primary, because when I was in here I was in the low group, but then later I tend[ed] to be in the highest one. But, I was not really confident because I would be scared if someone laughed at me if I said something wrong.

Rani: $\quad$ Yeah. It's like they're labelling you to sets of knowledge, because in primary they make it like that. The teachers treat you like two-year-olds. And, all the girls in the higher levels, they get to learn secondary stuff and we just learn, like...

Salima: The stuff we already learnt.

This extract highlights the costs of setting to students' perceptions of school, and their relations with teachers (Anaya and Riya's words also speak to findings from prior studies concerning teachers' lower expectations of pupils in lower attainment groups; see Jackson, 1964; Suknandan \& Lee, 1999; Hallam \& Ireson, 2005). Riya again articulates the (negative) impact of setting on her self-confidence, 
and relations with peers. These themes are concentrated by Rani, in her invocation of the infantalisation experienced by those designated to low attainment groups ('treat you like two-yearolds'), and the 'them and us' constructions encouraged by segregation by attainment ('all the girls in the higher levels...'). This lends support to our suggestion that attainment grouping not only comprises social segregation but also facilitates cultural perpetuation and exacerbation of this segregation between pupil groups within school contexts (see also Ball, 1981). Rani's point is affirmed by Salima, whose claim that lower sets are taught 'the stuff we already learnt' succinctly expresses frustration, futility, and alienation. Concluding this section of the interview, Anaya asserts, "Sets ruin your self-esteem."

This reported infantalisation of students in low sets was attested and even adopted by other pupils. Considering the experiences of pupils in low sets, top-set higher SES students Fred (White British) and Brian (White and Asian mixed heritage) consider:

Fred: I can't really say much because, I don't know, I'm in a higher set so I don't really know. I'd imagine they felt quite a lot less confident about themselves, yes, but then in a way I think they're congratulated a lot more for what they do, regardless of what it is, than we are. So, I think that probably cancels each other out and so it comes around a bit neutral, really.

I: $\quad$ That's interesting.

Brian: I think... yes, you are...if you say rewarded, l'd say patronised a lot more for what you achieve. It's like... let's say Set Four was a baby, and then Set One was a fully grown person. You'd see a baby walking and you're like, 'Oh, congratulations', like, 'Wow. How are you doing that?' You see a fully grown person walking and you don't bat an eyelid.

Despite his original defence that he lacks experience to comment, Fred proceeds to voice his belief that low set pupils receive meaningless praise; and Brian affirms Fred's view with an exemplar that tellingly uses the analogy of a baby. In this way, a set of disparaging assumptions are projected on to low set pupils, who are constructed as barely functioning and inane objects of patronage. Again, from a psycho-social perspective this example may be read as one of projection, wherein vulnerabilities are split off from top-set pupils and projected on to low set pupils who are pathologised and Othered. 
Arguing that affective transactions become 'sedimented' in classed habitus, Reay (2015) maintains that,

The learning that comes through inhabiting pathologised spaces within the field often results in a predilection for shame, fear, anxiety, or even righteous indignation, while the internalisation of social inequalities in the privileged can result in dispositions of superiority, entitlement, disdain but also a predilection for guilt, ambivalence and discomfort. (p. 12)

We argue that this analysis may be extended to attainment grouping (which, as we have explained, also tends to reflect social class trends - as well as those of ethnicity and gender). Fred and Brian's words evoke superiority, disdain and perhaps entitlement, but also some ambivalence; and guilt and discomfort was certainly expressed by some students. For example, looking back at her primary school experience, Alexis (mixed attainment class, White European, middle SES, School E) explains, "Because my friend, she is really good at maths, but she was put in the bottom group, and I think that ruined her confidence in maths so I felt really sorry for her. But I couldn't do anything of course. [..] I'm just a student."

However, Nissa (sets 2 and 5, White and African mixed heritage, higher SES, School C) evokes the shame and anxiety of inhabiting the 'pathologised space' (Reay, 2015) of the bottom set for maths. He affirms that set placement affects the way that students think about their abilities, and whether they enjoy school, explaining his views by saying,

Okay, let's say you've just found out that you're in a set and you don't like it there, the bottom set. For maths I'm in the bottom set and it was hard for me to tell my mum because I thought she'd be disappointed. But because in English I'm in Set 2 my mum is proud of me, like really proud, and I was proud saying it.

Students in lower sets likely have a range of methods for seeking defence from such shame, including 'moral defence' (see Celani, 2010), internalisation, and/or more ambivalent responses (see Lucey \& Reay, 2002). For example, Martina (sets 3, unknown mixed heritage, low SES, School D) defends setting as "good, because if people need more help". However, she then projects discomfort onto 'people' in low sets: 
people might be a bit upset about the fact that other people... that maybe they might feel a bit left out and everything, that they're not smart enough for the other groups. Yeah, that they're not good enough.

And then goes on to articulate her despair:

It makes me think, "Why can't I be taught with everyone else who's in the top group?" And then I try my best and I do try my best. Even though it's my best and I get put low - not low - but in a different group than the high group, so it feels like if that's my best and this is all I can do, what can I do?

In other words, the moral defence position, that legitimates her relatively low set placement through meritocracy and a need to receive additional help, cannot protect her from the feelings of exclusion and devaluation she articulates, and demands she internalise the message of 'not smart enough' in spite of her hard work and efforts at self-improvement.

Likewise Kevin (sets 4, White European, low SES, School C) also appears to have internalised his set level, explaining, "I've heard people, they like freak out about being moved down a set and then they even get jealous if people get moved up a set. It's like, 'Don't worry about it. Just get used to it'." This fatalistic approach seems to defend against the vulnerable engaged approach Kevin projects onto others, but potentially has negative consequences for his learning (as he embraces his low placement) besides questions about the psychic implications of this approach.

At the other end of the spectrum of experience, Robin (sets 1, White and Black Caribbean mixed heritage, low SES, School C) explains that he likes being in the top set, and that it makes him feel "confident because I know I have good work."

Such self-esteem engendered resentment from some of those in other sets, as this extract from a Maths Set 2 focus group at School B illustrates:

Adam: $\quad$ Yeah, in Set 1 they think they're so smart because they're in a high set.

Janne: No.

Adam: 'Oh, I'm better than you because I'm in the higher set'. 
Tavi: $\quad$ They do that a lot, because there are some people in set 1 for English, that they think just because they're intelligent they don't need to learn anything.

Janne: Yes.

Tavi: $\quad$ So they start being silly instead of starting to do their work.

Adam: $\quad$ You never know. They could go down.

Tavi: $\quad$ Yeah, they could. One of them has already been at our level.

Adam: Who?

Tavi: $\quad$ Tyrell.

Adam: $\quad$ From what?

Tavi: $\quad$ From Set 1.

Besides illustrating social divisions precipitated by setting, and a less positive implication of the apparent high confidence of some of those in the top sets, this extract provides a further example of splitting and projection as a means of defence. Insecurities of being in a lower set are split off by projecting complacency and snobbery to those in the top set, and the group construct themselves morally superior and as wisely knowing (in comparison to their top set peers).

\section{Positive constructions of attainment grouping}

Not all young people presented attainment grouping as harmful, and some even constructed it as beneficial. For example, in the following extract a set 2 maths focus group at School B presents setting as motivating hard work:

I: $\quad$ And what about the low sets, set number 3 or set number 4 for that?

Adam: The try and achieve higher.

Tavi: $\quad$ They try and achieve higher.

Adam: $\quad$ They work harder.

Tavi: $\quad$ They need to try to do....the teacher says that when you go to set 3 or set 2 it doesn't actually matter. You'll be learning the same thing, but in an easier way. But if you try even harder than the teacher's explaining to you, you might have a chance to go to on to a level higher.

Kashvi (mixed attainment class, South Asian, high SES, School F) agrees with this suggestion that it works for everyone, and even argues that placement in a lower set can support confidence: 
I think it would affect what they think about themselves but I think in a good way. Because the high attainers, like the people who get the higher grades, they'd feel good about themselves because obviously they've gotten the higher grades. People who haven't gotten as much of a high grade, they probably would build up their confidence, build up their determination, and try and try until they get to the higher stage. All around... good about themselves.

What these quotes also illustrate is a faith in meritocracy and work ethic: set designation is seen as reflecting merit and rewarding excellence, and placement in a lower set incentivises hard work and 'determination' to move upwards. Research shows that this faith may be misplaced, as set designation reflects other factors besides prior attainment (several reviews and empirical studies have shown a closer relationship between attainment group designation and pupil socioeconomic background than prior attainment [Jackson, 1964; Kutnick et al, 2005; Dunne et al, 2007]); and research has also shown that, once placed in a particular attainment group, pupils are likely to stay in the group irrespective of their progress [Flores, 1999; Dunne et al, 2007; Mujis et al, 2010).

Other students saw both strengths and weaknesses to attainment grouping. Some of these students presented it as protective to those in low attainment groups, who they constructed as potentially intimidated and daunted by the higher attainers if working with them in a mixed attainment class:

Like, obviously there's a difference between thriving in the bottom set and then moving up a set but really struggling there, and sometimes you wish there was a middle set in between two sets. So I think it can be harsh on people's confidence if they're, kind of, they often find they see someone else doing really, really well in something that they thought everyone struggled with. [...] I think the fact that they've even put us in sets is actually kind in a way, that they've done that. (Monica, sets 1, White British, unknown SES, School D).

Notably, these young people were not themselves in low set groups. Other students pointed out that students are different and may be affected (or not affected) by attainment grouping in different ways. Beatrice (sets 1, Black African heritage, middle SES, School C) considers, "if you're not in the top set, people might think, 'Oh, I'm not in the top set,' so they might not... like, they'll feel down so they won't do their best in the set they're in. But for other people, they, kind of, like, enjoy it and they don't mind." And Janet (sets 4 and 3, Black African heritage, unknown SES, School C) says of her 
set placement, “it doesn't affect me, how I think about myself. I'm still confident even though I'm not in the top set." These ambivalent and/or 'philosophical' articulations may be seen to reflect the ways we move in and out of various psychic positions (Klein, 1963), and attainment of the 'depressive position' which accepts that good and bad can coexist in the same object. In this sense, we may read these expressions as students' emotional work towards repairing the consequences of setting in relation to their sense of self (see Lucey \& Reay, 2002).

\section{Discussion/Conclusion}

To summarise our findings, we have established significant relationships between set level and pupil self-confidence - both for the subjects of maths and English, and for general self-confidence. These findings bear significance for the research field and for practice for two key reasons. Firstly, due to the clarity of patterns across an unusually large sample of Year 7 students, we clarify prior debates in the literature about the impact or otherwise of setting on self-confidence and self concept. Our findings support those studies (for example Houtte et al [2012], Ireson \& Hallam [2012], Lui [2005]) that find an association between attainment group level and self confidence/self concept; and challenge those studies discussed above that fail to find an association. Indeed, our findings go beyond those of Hallam and Ireson (2009) in demonstrating the set level and self confidence relationship for maths. Hence our findings have established the presence of this relationship for both subjects historically elevated within the English education system and elsewhere - Maths, and national language. And secondly, our study is innovative in the exploration of a potential relationship between set level and general self confidence in learning: prior studies such as those of Ireson and Hallam $(2001 ; 2009)$ had investigated general self-concept, but not according to set level. Their findings on general self-concept according to extent of attainment grouping in a school have been mixed (Ireson \& Hallam, 2001; 2009): in contrast our findings show a relationship between set level and general self-confidence in learning. This finding is especially significant because it suggests that setting may have broader implications for learning beyond the specific subjects in which setting takes place. Overall, our findings lend strong support to the suggestion that the impact of labelling on pupil self-confidence is one explanation for the poorer progress of those in low attainment groups. Nevertheless, a range of questions remain and need further exploration, including the impact of numbers of sets within a school on student self-perception (as this varied widely within our school sample), and the extent to which we might assume or expect that pupils with different levels of prior attainment will have different levels of confidence in their learning. And while space restrictions have precluded our reporting findings on other facets of social identity (e.g. ethnicity, 
social class, gender, etc.) in relation to set placement and self-confidence, these elements remain important and will be reported elsewhere.

In contrast to most other large-scale studies on the topic of attainment grouping, our study has benefitted from a qualitative component, which has found that Year 7 students are aware of the labelling effects of setting. Indeed many of them volunteered accounts of the self-fulfilling prophecy that set designation may precipitate. Year 7 students' clear awareness of the issues at stake, and their frequent articulations of problematic - and some beneficial - elements of setting, belies any notion that students do not understand and/or are unaware of setting (see Marks, 2013, for discussion of teacher perceptions that students are not aware of attainment grouping). We have also attempted to tease out some of the psycho-social implications of attainment grouping, and the ways in which young people use set hierarchies to split and project deficiencies, typically onto denigrated low sets, but also sometimes to top sets who are constructed as smug and conceited. Most distressingly, we have presented some material wherein students speak of the pain and shame of their ascribed set group (see also Marks, 2016, for findings in primary schools). These findings, we would assert, need to be taken seriously: both for the deleterious effects on individual psyches and the consequences for student outcomes and wellbeing therein, but also with regard to the detrimental impact on social mixing and harmony within school contexts.

The findings concerning infantalisation and denigration of low attainment groups need to be taken especially seriously by educators. Here it is important to also reiterate the concern that Special Educational Needs - conflated by some pupils with low attainment - remains a denigrated labelviii The impact of labelling on low attainers, and those designated 'SEN', requires urgent attention.

It is also worth noting the faith that many students had in the meritocracy of attainment grouping: that set placement directly reflects merit, and that those in lower groups who excel will be rewarded by moving up, while those in higher groups who make less progress will be moved down accordingly. As we observe above, evidence suggests that in fact practice in schools frequently does not reflect these assumptions (see Flores, 1999; Dunne et al, 2007; Dunne et al, 2011; Hallam \& Ireson, 2005). Indeed, set placement based exclusively on prior attainment, and rigorous periodic set movement (again based exclusively on prior attainment) are two of the requirements demanded within our 'Best Practice in Setting' intervention. Often schools have found these measures hard to implement in practice for a variety of reasons (see Taylor, 2017; Taylor et al, 2017). Yet schools operating setting need to consider carefully the rationales justifying their practice of attainment grouping: if setting is 
not actually by attainment in practice, it questions the validity of adopting this structure in the first place. Schools need to ensure that a range of important different ends - student outcomes, wellbeing, community, and progress - are balanced so far as possible, and that practices adopted are justified by research evidence. This reflection is needed to ensure that those students most in need of support to improve are not being further held back by grouping practices.

\section{References}

Archer, L., Hollingworth, S., Mendick, H. (2010). Urban youth and schooling. Maidenhead: Open University Press.

Ball S. (1981). Beachside Comprehensive: a case-study of secondary schooling. Cambridge: Cambridge University Press.

Bandura A. (1997). Self-efficacy: The exercise of control. New York: W.H.Freeman and Company.

Becker H. (1973). [1963]. Outsiders. New York: Free Press.

Belfi B., Goos M., De Fraine B., Van Damme J. (2012). The effect of class composition by gender and ability on secondary school students' school well-being and academic self-concept: A literature review. Educational Research Review, 7, 62-74.

Boaler J. (1997). Setting, Social Class and Survival of the Quickest. British Educational Research Journal, 23, 575-595.

Boaler J., Wiliam D., Brown M. (2000). Students' Experiences of Ability Grouping-disaffection, polarisation and the construction of failure. British Educational Research Journal, 26, 631-648.

Boaler, J., \& Wiliam, D. (2001). Setting, streaming and mixed-ability teaching. In J. Dillon \& M. Maguire (Eds.), Becoming a teacher (2nd ed.). (pp. 173-181). Maidenhead: Open University Press.

Brown M., Brown P., Bibby T. (2008). 'I would rather die': Reasons given by 16 year olds for not continuing their study of mathematics. Research in Mathematics Education, 10(1) 3-18.

Celani D. (2010). Fairbairn's Object Relations Theory in the Clinical Setting. Columbia University Press.

Chmielewski A. K., Dumont H., Trautwein U. (2013). Tracking Effects Depend on Tracking Type: An International Comparison of Students' Mathematics Self-Concept. American Educational Research Journal, 50, 925-957.

Dracup T. (2014). The Politics of Setting, https://giftedphoenix.wordpress.com/2014/11/12/thepolitics-of-setting/ Retrieved: $6^{\text {th }}$ February 2017.

Dunne M., Humphreys J., Sebba J., Dyson A., Gallanmaugh F., Muijs D. (2007). Effective teaching and learning for pupils in low attaining groups. London: DCSF. 
Dunne, M., Humphreys, S., Dyson, A., Sebba, J., Gallannaugh, F., \& Muijs, D. (2011). The teaching and learning of pupils in low-attainment sets. Curriculum Journal, 22(4), 485-513.

Dwek C. (2006). Mindset: The new psychology of success. New York: Random House.

Dytham S. (2016). Relational popularity and social status in secondary school. Unpublished PhD thesis, University of Warwick.

Education Endowment Foundation Toolkit (2016).

http://educationendowmentfoundation.org.uk/toolkit/ Retrieved: $6^{\text {th }}$ February 2017.

Finley, M.K. (1984). Teachers and tracking in a comprehensive high school. Sociology of Education, 57, 233-243.

Flores J. (1999). Tracking middle school students for instruction: a study of homogeneous and heterogeneous grouping. California State University San Marcos. PhD.

Francis, B. (2000). Boys, girls and achievement. London: Routledge.

Francis, B., Archer, L., Hodgen, J., Pepper, D., Taylor, B., \& Travers, M.-C. (2017). Exploring the relative lack of impact of research on 'ability grouping' in England: a discourse analytic account. Cambridge Journal of Education, 47, 1-17.

Freire P. (1097). Pedagogy of the Oppressed. New York: Herder \& Herder.

Hallam S., Ireson J. (2005). Secondary School Teachers' pedagogic practices when teaching mixed and structured ability classes. Research Papers in Education, 20, 3-24.

Hallam, S., Ireson, J., Lister, V., Andon Chaudhury, I. and Davies, J. (2003). Ability grouping in the primary school: a survey. Educational Studies, 29, 69-83.

Houtte M. V., Demanet J., Stevens P. (2012). Self-esteem of academic and vocational students: Does within-school tracking sharpen the difference? Acta Sociologica, 55, 73-89.

Hollway W., Jefferson T. (2000). Doing Qualitative Research Differently. London: Sage.

Ireson J., Hallam S. (2001). Ability Grouping in Education. London: Paul Chapman Publishing.

Ireson J., Hallam S., Plewis I. (2001). Ability grouping in secondary schools: Effects on pupils' selfconcepts. British Journal of Educational Psychology, 71, 315-326.

Ireson J., Hallam S., Hurley C. (2005). What are the effects of ability grouping on GCSE attainment? British Educational Research Journal, 31, 443-458.

Ireson J., Hallam S (2009). Academic self-concepts in adolescence: Relations with achievement and ability grouping in schools. Learning and Instruction, 19, 201-213.

Jackson B. (1964). Streaming: An Education system in miniature. London: Routledge \& Kegan Paul. 
Kelly, S. (2004) Are teachers tracked? On what basis and with what consequences? Social Psychology of Education, 7: 55-72.

Klassen R. (2004). Optimism and realism: A review of self-efficacy from a cross-cultural perspective. International Journal of Psychology, 39, 205-230.

Klein M. (1952). Developments in Psycho-Analysis. London: Hogarth Press.

Klein M. (1963). Our Adult World and Other Essays. London: Heinemann.

Kulik C.-L. C., Kulik J.A. (1982). Effects of Ability Grouping on Secondary School Students: A MetaAnalysis of Evaluation Findings. American Educational Research Journal, 19, 415-428.

Kutnick P., Sebba J., Blatchford P., Galton M., Thorpe J., with Maclntyre H., Berdondini L. (2005). The Effects of Pupil Grouping: Literature Review. Research Report 688: London: DfES.

Lemert E. M. (1951). Social Pathology. New York: McGraw-Hill.

Liem G. A. D., McInerney D., Leung A.S. (2015). Academic Self-Concepts in Ability Streams:

Considering Domain Specificity and Same-Stream Peers. The Journal of Experimental Education, 83, 83-109.

Linchevski L., Kutscher B. (1998). Tell me with whom you're learning and I'll tell you how much you've learned: mixed-ability versus same-ability grouping in mathematics. Journal for Research in Mathematics Education, 29, 533-54.

Liu W. C., Wang CK., Parkins E.J. (2005). A longitudinal study of students' academic self-concept in a streamed setting: The Singapore context. British Journal of Educational Psychology, 75, 567-586.

Lucey H. (2010). Sisters' stories: a psychosocial perspective on families, peers and social class in resistance and conformity to education. Gender and Education, 22, 447-462.

Lucey H., Melody J., Walkerdine V. (2006). Uneasy hybrids: psychosocial aspects of becoming educationally successful for working class young women. In Arnot, M., Mac an Ghaill, M., (Eds.) The RoutledgeFalmer Reader in Gender and Education (pp. 238-252). London: RoutledgeFalmer.

Lucey H., Reay, D. (2002). A market in waste: psychic and structural dimensions of school-choice policy in the UK and children's narratives on 'demonized' schools'. Discourse: Studies in the cultural politics of education, 23, 253-266.

Marsh H. W. (1984). Self-Concept, Social Comparison, and Ability Grouping: A Reply to Kulik and Kulik. American Educational Research Journal, 21, 799-806.

Martin M.O., Mullis I.V.S. (Eds.) (2012). Methods and Procedures in TIMSS and PIRLS 2011. Chestnut Hill, MA: TIMSS \& PIRLS International Study Center, Boston College.

Marks, R. (2013). "The blue table means you don't have a clue": the persistence of fixed-ability thinking and practices in primary mathematics in English schools. FORUM, 55, 31-44.

Marks, R. (2016). Ability Grouping in Primary Schools. London: Critical Publishing. 
Marsh H. W. (2008). The Big-fish-little-pond-effect stands up to critical scrutiny: Implications for theory, methodology and further research. Educational Psychology Review, 20, 319-350.

Merton R.K. (1948). The Self Fulfilling Prophecy. Antioch Review, 8, 195.

Monchy, M., Pijl, S.J., \& Zandberg, T. (2004) Discrepancies in judging social inclusion and bullying of pupils with behaviour problems. European Journal of Special Needs Education, 19, 317-330.

Mulkey L. M., Catsambis S., Steelman L., Crain R. (2005). The long-term effects of ability grouping in mathematics: A national investigation. Social Psychology of Education, 8, 137-177.

Muijs, D., Dunne M. (2010). Setting by ability-or is it? A quantitative study of determinants of set placement in English secondary schools. Educational Research, 52, 391-407.

Norwich, B., \& Kelly, (2004) Pupils' views on inclusion: moderate learning difficulties and bullying in mainstream and special schools. British Educational Research Journal, 30, 43-65.

OECD. (2014). Are grouping and selecting students for different schools related to students' motivation to learn? PISA in focus 39. Paris: OECD.

Pajares F. (1996). Self-Efficacy Beliefs in Academic Settings. Review of Educational Research, 66, 543578.

Preckel F., Gotz T., Frenzel A. (2010). Ability grouping of gifted students: Effects on academic selfconcept and boredom. British Journal of Educational Psychology, 80, 451-472.

Reay D. (2015). Habitus and the psychosocial: Bourdieu with feelings. Cambridge Journal of Education, 45, 9-23.

Rubie-Davies (2007). Classroom interactions: Exploring the practices of high-and lowexpectation teachers. British Journal of Educational Psychology, 77, 289-306.

Slavin R. (1990). Achievement effects of ability grouping in secondary schools: a best evidence synthesis. Review of Educational Research, 60, 471-499.

Suk Wai Wong, M., Watkins, D. (2001). Self-esteem and Ability Grouping: A Hong Kong investigation of the Big Fish Little Pond Effect. Educational Psychology, 21, 79-87.

Sukhnandan L., Lee B. (1999). Streaming, Setting and Grouping by Ablility. Slough: NFER.

Steenbergen-Hu S., Makel M.C., Olszewski-Kubilius P. (2016). What One Hundred Years of Research Says About the Effects of Ability Grouping and Acceleration on K-12 Students' Academic Achievement: Findings of Two Second-Order Meta-Analyses. Review of Educational Research, 86, 849-899.

Taylor, B. (2017) 'Why is it difficult for schools to establish equitable practices in allocating students to attainment 'sets'?' Paper presented at British Educational Research Association Conference, University of Sussex, Sept $5^{\text {th }}, 2017$.

Taylor, B., Francis, B., Archer, L., Hodgen, J., Pepper, D., Tereshchenko, A., Traves, M-C. (2017). Factors deterring schools from mixed attainment teaching practice. Pedagogy, Culture \& Society, 25, 327-345. 
Vogl, K., Preckel, F. (2014). Full-Time Ability Grouping of Gifted Students Impacts on Social SelfConcept and School-Related Attitudes. Gifted Child Quarterly, 58, 51-68.

Walkerdine V., Lucey H., Melody J. (2001). Growing Up Girl. London: Virago.

\section{Notes}

\footnotetext{
'The authors do not subscribe to conceptions of 'ability' as ascribed and fixed: rather we see it as malleable, and prior attainment to reflect a range of societal factors that impact educational progress and outcome. Hence our use of inverted commas, and our reference where possible to 'attainment grouping' rather than 'ability grouping'.

ii Teacher perception of pupils and their potential has also been shown to have a strong impact on pupil outcomes, see Francis et al (2017) for further discussion.

iii Setting is a form of attainment grouping whereby pupils are grouped together by prior attainment in the study of particular subjects. It is more flexible than tracking (streaming) wherein students are banded into the same 'ability' groups for most or all subjects; as in the case of setting, a pupil might be in a high set for one subject and a low set for another. However, often the practices are blurred - for example setting can take place in addition to tracking, and/or there can be clustering of set applications across a number of subjects. Setting is prevalent in English secondary (high school) education, and increasingly in primary schooling (Francis et al, 2017; Hallam \& Ireson 2007).

iv See endnote iv

${ }^{\vee}$ NFER are commissioned by the Education Endowment Foundation to perform the post-testing and to evaluate our key intervention outcomes. See https://educationendowmentfoundation.org.uk/ourwork/projects/best-practice-in-grouping-students/ for information on the wider study, and the published RCT protocols.

vi 'Special Educational Needs' is the official label used in the British education system to refer to those learners designated as having learning problems or disabilities.

vii See Archer et al (2010) for evidence of the import of 'respect' for high school students.

viii See Norwich \& Kelly (2004) and Monchy et al (2004) for findings on bullying of young people with SEN in mainstream schools.
} 